\title{
Deteksi Emosi Media Sosial Menggunakan Pendekatan Leksikon dan Natural Language Processing
}

\author{
Arif Nur Rohman ${ }^{1}$, Ema Utami ${ }^{2}$, Suwanto Raharjo ${ }^{3}$ \\ Magister Teknik Informatika \\ Universitas AMIKOM Yogyakarta \\ Yogyakarta, Indonesia \\ e-mail: ${ }^{1}$ arifrahman2592@gmail.com@, ${ }^{2}$ ema.u@amikom.ac.id, ${ }^{3}$ wa2n@nrar.net \\ Diajukan: 19 Agustus 2019; Direvisi: 20 September 2019; Diterima: 28 September 2019
}

\begin{abstract}
Abstrak
Emosi memenuhi kehidupan manusia setiap waktu. Emosi mempengaruhi hubungan sosial, ingatan dan bahkan dalam pengambilan keputusan. Saat ini, orang cenderung mengekspresikan emosi melalui media sosial seperti Facebook dalam bentuk gambar, video, dan teks pada umumnya. Deteksi emosi pada teks merupakan bidang penelitian yang baru dan banyak diteliti khususnya dibidang linguistik. Penelitian ini menggunakan EmoLex sebagai leksikon yang digunakan untuk mendeteksi emosi pada suatu teks. Kosa kata pada EmoLex diperluas dengan pencarian sinonim menggunakan Kateglo API. EmoLex digunakan sebagai leksikon 8 kategori emosi Plutchik dan sentimen. EmoLex tersedia dalam 105 bahasa berbeda termasuk Indonesia yang mana mengandung 14.182 kata yang kemudian diperluas dengan pencarian sinonim menggunakan Kateglo API. Pencarian sinonim menghasilkan 20.690 kata sehingga memperoleh hasil akhir leksikon emosi yang berisi 34.872 kata. Pengujian menunjukkan bahwa leksikon emosi mampu mendeteksi $55.45 \%$ atau 15.357 dari 27.696 kata yang diperoleh dari update status pengguna Facebook dalam melakukan pendeteksian emosi, sebanyak 100 update status diambil dari facebook. Selanjutnya update status tersebut diperbaiki menggunakan Natural Language Processing (NLP). Hasil perbaikannya dinilai dengan leksikon emosi yang telah dibuat sebelumnya. 26 dari 100 update status dapat diketahui label emosinya. Hasil validasi terdapat 16 update status atau 61,53\% label emosinya akurat.
\end{abstract}

Kata kunci: Deteksi emosi teks, EmoLex, Kateglo API, Leksikon emosi.

\begin{abstract}
Emotion fills human life all the time. Emotions affect social relationships, memories and even decision making. Nowadays, people tend to express emotions through social media like Facebook in the form of pictures, videos and text in general. Text is the most widely used form of communication that offers many characteristics that make it the best choice for analyzing artificial emotional intelligence data. This study uses EmoLex as a lexicon that is used to detect emotions in a text. The vocabulary on EmoLex is expanded by synonym search using the Kateglo API. EmoLex is used as a lexicon of 8 categories of Plutchik emotions and sentiments. EmoLex is available in 105 different languages including Indonesian which contains 14,182 words which are then expanded by synonym search using the Category API. Synonym search resulted in 20,690 words so that the final emotional lexicon contained 34,872 words. The test show that the emotional lexicon is able to detect 55.45\% or 15,357 of 27,696 words obtained from Facebook user status updates. In detecting emotions, as many as 100 status updates are taken from Facebook. Furthermore, the status update is corrected using Natural Language Processing (NLP). The results of its improvement are assessed by emotional lexicon that has been made before. 26 out of 100 status updates can be labeled as emotional. The result is there are 16 status updates or $61.53 \%$ accurate emotional labels.
\end{abstract}

Keywords: teks emotion detection, EmoLex, Kateglo API, emotion lexicon.

\section{Pendahuluan}

Manusia penuh dengan emosi. Emosi menambah cita rasa hidup dengan memperkenalkan cara mengekspresikan perasaan mereka dalam bentuk komunikasi [1]. Analisis emosi manusia telah menjadi topik penelitian dalam berbagai disiplin ilmu, seperti Ilmu Kognitif, Psikologi, dan berkat difusi media sosial, itu juga menarik minat para ilmuwan komputer [2]. Memahami emosi memainkan peran utama 
dalam pengembangan interaksi manusia-komputer. Ini membantu mengeksplorasi tren masyarakat terhadap berbagai jenis bidang terutama masalah psikologis [3]. Emosi memengaruhi kehidupan manusia sehari-hari seperti hubungan sosial, ingatan, dan bahkan pengambilan keputusan [4]. Sebagian besar pekerjaan penelitian yang dilakukan di bidang klasifikasi emosi umumnya menggunakan model Ekman [4]. Ekman mengidentifikasi enam emosi dasar manusia, yaitu marah, jijik, takut, bahagia, sedih, dan kaget atau kejutan [5].

Situs media sosial seperti Facebook adalah tempat utama bagi orang untuk mengekspresikan emosi, pendapat dan menceritakan kehidupan sehari-hari mereka. Facebook memiliki fitur update status yang memungkinkan penggunanya melakukan posting gambar, video, dan terutama melalui teks yang akan tampil pada timeline pengguna terkait [6]. Selain itu, Facebook merupakan media sosial dengan jumlah pengguna paling banyak di Indonesia, yaitu mencapai 130 juta pengguna aktif bulanan.

Natural Language Processing (NLP) merupakan salah satu cabang ilmu AI yang berfokus pada pengolahan bahasa natural. Bahasa natural adalah bahasa yang secara umum digunakan oleh manusia dalam berkomunikasi satu sama lain. Penelitian menggunakan pendekatan leksikon dan NLP sebelumnya telah digunakan untuk penyaringan gejala depresi pada pengguna Twitter, hasilnya diperoleh bahwa pendekatan leksikon dan NLP memiliki akurasi lebih baik dari pada menggunakan pendekatan machine learning [7]. Penelitian ini bertujuan untuk mendeteksi kondisi emosi pada media sosial Facebook menggunakan pendekatan leksikon dan NLP.

\section{Metode Penelitian}

Gambaran umum deteksi kondisi emosi pada teks media sosial Facebook dengan pendekatan leksikon dan NLP dijelaskan pada Gambar 1.

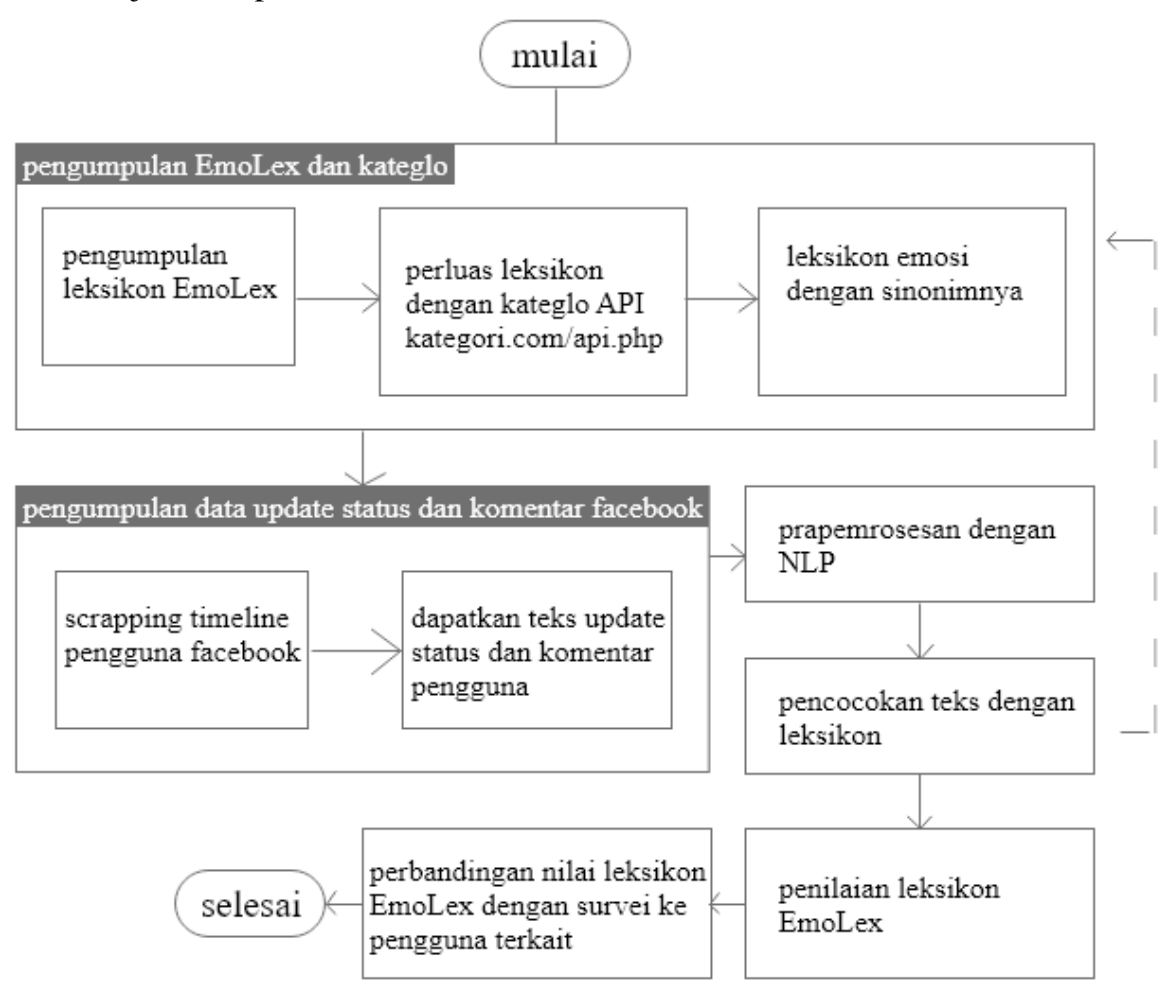

Gambar 1. Gambaran umum deteksi kondisi emosi pada media sosial Facebook.

Pada Gambar 1 dijelaskan gambaran umum deteksi kondisi emosi pada media sosial Facebook secara keseluruhan dimulai dari pembentukan leksikon emosi dari EmoLex. Untuk meningkatkan jumlah kosa kata EmoLex, peneliti memanfaatkan Kateglo API sebuah layanan berbasis web untuk mencari sinonim dari tiap kata yang ada pada EmoLex. Tiap sinonim yang diperoleh diberi label emosi yang sama dengan yang ada pada EmoLex. Selanjutnya pengumpulan data berbentuk teks yang diperoleh dari update status dan komentar pengguna Facebook. Pemilihan data teks karena data teks memiliki kelebihan mudah dikelola dan ruang penyimpanan yang relatif kecil dibandingkan dengan gambar atau video. Data yang terkumpul dilakukan prapemrosesan guna perbaikan data menggunakan pendekatan NLP. Fitur NLP yang 
akan digunakan adalah word normalizer, tokenizer dan stemmer. Update status hasil perbaikan prapemrosesan dengan NLP diberikan penilaian emosi menggunakan leksikon emosi yang dibuat. Validasi dilakukan dengan cara survei langsung pada pengguna terkait sebagai author dari update status, hasil pelabelan emosi dengan leksikon akan dibandingkan dengan hasil penilaian emosi dari survei, hasil yang sama akan disebut akurat.

\section{Hasil dan Pembahasan}

\subsection{Mendapatkan Leksikon EmoLex}

Peneliti melakukan tinjauan langsung pada situs resmi yang menyediakan informasi tentang EmoLex https://saifmohammad.com/WebPages/NRC-Emotion-Lexicon.htm. Dari tinjauan langsung peneliti menemukan bahwa EmoLex tersedia dalam 105 bahasa di dunia termasuk Indonesia dan memiliki 14.182 unigram untuk bahasa Indonesia. EmoLex sudah diberi label secara manual dengan delapan emosi dasar Plutchik (anger, fear, anticipation, trust, surprise, sadness, joy, and disgust) dan dua sentimen (negatif dan positif) [10]. Contoh EmoLex ditunjukkan pada Tabel 1.

Tabel 1. Contoh EmoLex.

\begin{tabular}{lcccccccccc}
\hline & Positif & Negatif & Anger & Anticipation & Disgust & Fear & Joy & Sadness & Surprise & Trust \\
\hline benci & 0 & 1 & 1 & 0 & 1 & 1 & 0 & 0 & 0 \\
\hline senang & 1 & 0 & 0 & 1 & 0 & 0 & 1 & 0 & 0 \\
\hline hina & 0 & 1 & 1 & 0 & 0 & 1 & 0 & 0 & 0 \\
\hline abnormal & 0 & 1 & 0 & 0 & 1 & 0 & 0 & 0 & 0 \\
\hline mendadak & 0 & 0 & 0 & 0 & 0 & 0 & 0 & 0 & 1 \\
\hline gagal & 0 & 1 & 0 & 0 & 0 & 0 & 0 & 1 & 0 \\
\hline kekejian & 0 & 1 & 1 & 0 & 1 & 1 & 0 & 0 & 0 \\
\hline mengerikan & 0 & 1 & 0 & 0 & 1 & 1 & 0 & 0 & 0 \\
\hline tepat & 1 & 0 & 0 & 0 & 0 & 0 & 0 & 0 & 0 \\
\hline prestasi & 1 & 0 & 0 & 1 & 0 & 0 & 1 & 0 & 0 \\
\hline
\end{tabular}

Setiap kata pada EmoLex bisa saja memiliki lebih dari label emosi. Label emosi ditandai dengan angka 1 jika memiliki label dan 0 jika tidak. EmoLex diberikan dalam format .xlsx yang dapat dibukan dengan software Ms Excel. Hasil unduhan EmoLex dibersihkan untuk membuang 104 bahasa lain selain Indonesia. Delapan label emosi Plutchik serta sentimen positif dan negatif dibiarkan apa adanya sebagai label leksikon. Selanjutnya simpan leksikon yang ada dalam database MySQL agar mudah digunakan pada tahap berikutnya.

\subsection{Perluasan Leksikon EmoLex}

Fitur pencarian sinonim pada Kateglo API dimanfaatkan penulis untuk memperluas leksikon EmoLex yang ada. Kateglo merupakan kamus, tesaurus, dan glosarium bahasa Indonesia [7]. Kateglo memiliki 72253 entri kamus, 191200 entri glosarium, 2012 entri peribahasa, serta 3423 entri singkatan dan akronim. Kateglo membuka layanan akses berbasis web yang dapat diakses menggunakan Application Programming Interface (API) melalui kateglo.com/api.php yang dapat digunakan untuk pencarian sinonim. Pencarian sinonim leksikon EmoLex dilakukan satu persatu dari tiap kata yang ada pada EmoLex sebanyak 14.182 kata. Peneliti menggunakan tool yang dibuat secara mandiri dengan bahasa PHP agar pencarian sinonim tidak perlu dilakukan manual oleh manusia. Hasil dari tool ini selanjutnya disimpan pada database MySQL agar mudah dikelola. Cara kerja tool pencarian sinonim menggunakan Kateglo API seperti pada Gambar 2.

Tiap satu kata diambil dari leksikon EmoLex. Kemudian gunakan Kateglo API dengan parameter kata yang diperoleh dari EmoLex untuk mengakses database Kateglo menggunakan tool melalui Kateglo API, jika sinonim ditemukan, maka selanjutnya simpan semua sinonim yang ada ke dalam database baru sebagai database leksikon emosi. Jika tidak ditemukan, maka kata diabaikan dan tool kembali ke tahap awal untuk pencarian sinonim kata berikutnya. Dari sinonim yang diperoleh tidak hanya level 1 dan level 2 saja yang diambil, namun semua sinonim diambil dengan tujuan agar mendapatkan semua sinonim dari perluasan leksikon EmoLex. Diperlukan waktu 2 minggu untuk mendapatkan sinonim dari leksikon EmoLex dengan bantuan tool.

Hasil pencarian sinonim dari leksikon EmoLex menggunakan Kateglo API memperoleh 247.856 kata. Selanjutnya dari 247.856 kata dipersempit lagi dengan grouping kata. Maksud grouping kata adalah kata yang muncul lebih dari 1 kali maka akan tetap dihitung 1 karena label emosi dan sentimen mereka adalah sama. Sehingga hasil akhir pencarian sinonim memperoleh 20.690 kata. 


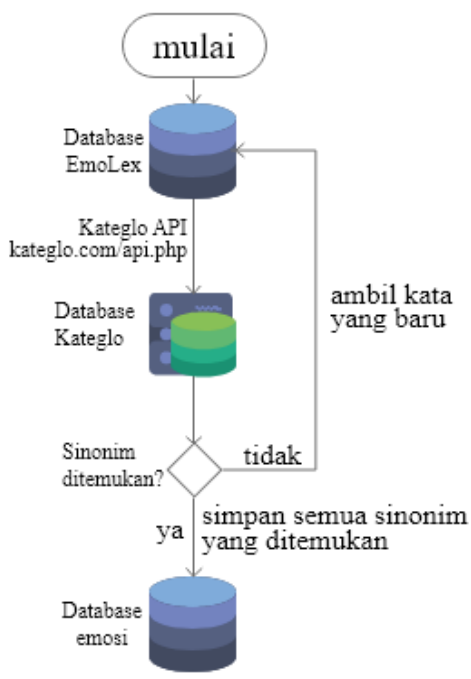

Gambar 2. Alur pencarian sinonim dengan Kateglo API.

\subsection{Leksikon Emosi}

Tidak semua kata pada EmoLex ditemukan sinonimnya, sehingga leksikon emosi dibuat tidak hanya dari EmoLex saja atau sinonim saja, namun penggabungan keduanya. Total leksikon EmoLex 14.182 ditambah sinonim 20.690 menjadi 34.872 kata sebagai leksikon emosi yang nantinya akan diuji menggunakan teks yang diambil dari Facebook. Contoh leksikon emosi terdapat pada Tabel 2.

Tabel 2. Contoh leksikon emosi penggabungan EmoLex dan sinonimnya.

\begin{tabular}{lccccccccccc}
\hline & positif & negatif & Anger & Anticipation & Disgust & Fear & Joy & Sadness & Surprise & Trust \\
\hline ceria & 1 & 0 & 0 & 1 & 0 & 0 & 1 & 0 & 0 \\
\hline senang & 1 & 0 & 0 & 1 & 0 & 0 & 1 & 0 & 0 & 1 \\
\hline
\end{tabular}

Pembagian kata ke dalam 8 kategori emosi Plutchik dan 2 sentimen (negatif dan positif) dijelaskan pada Tabel 3.

Tabel 3. Pembagian kata dalam 8 emosi dan sentimen.

\begin{tabular}{clc}
\hline Nomor & Kategori dan sentimen & Jumlah (kata) \\
\hline 1 & Anger & 4478 \\
\hline 2 & Fear & 5056 \\
\hline 3 & Anticipation & 4119 \\
\hline 4 & Trust & 5006 \\
\hline 5 & Surprise & 2971 \\
\hline 6 & Sadness & 4334 \\
\hline 7 & joy & 3105 \\
\hline 8 & Disgust & 3887 \\
\hline 9 & Positif & 7302 \\
\hline 10 & Negatif & 8522
\end{tabular}

Dalam EmoLex dan sinonimnya, 1 kata bisa saja mengandung lebih dari 1 kategori emosi dan sentimen [10], selain itu juga terdapat kata yang tidak mengandung emosi sama sekali namun mengandung sentimen, sehingga akumulasi Tabel 3 tidak dapat disamakan dengan hasil perluasan kata yang mendapatkan hasil 34.872 kata seperti dijelaskan di atas.

\subsection{Pengujian Kekayaan Leksikon Emosi}

Pengujian dilakukan untuk mengetahui kekayaan dari leksikon emosi yang telah dibuat. Cara pengujian diawali dengan pengumpulan bahan uji yang diperoleh dari update status pengguna Facebook yang dipilih secara acak. Update status yang digunakan hanyalah yang berbahasa Indonesia. Pengumpulan dilakukan dengan tool scrapping yang dibuat oleh peneliti. Tool ini bekerja dengan diberikan masukan username pengguna Facebook yang ingin diambil datanya. Keluaran dari tool ini berupa teks update status pengguna Facebook yang selanjutnya disimpan pada database MySQL untuk memudahkan pengelolaan.

Deteksi Emosi Media Sosial Menggunakan Pendekatan Leksikon dan Natural Language Processing (Arif Nur Rohman) 
Update status yang terkumpul dilakukan prapemrosesan untuk memperbaiki bahasa yang ada pada teks. Sebelum diuji pada leksikon, teks yang diperoleh dari Facebook dilakukan prapemrosesan sebagai berikut:

a. Membuang emoticon

Update status pada Facebook umumnya mengandung emoticon. Pada tahap ini emoticon dibuang karena makalah ini hanya membahas teks yang akan diuji pada leksikon.

b. Membuang URL

URL situs yang ada pada teks juga dihilangkan

c. Membuang karakter khusus

Karakter khusus seperti @ \#\$\% \&*+-_<>V[]\{\} dihilangkan karena tanda khusus tersebut dianggap kurang dapat memberikan arti.

d. Membuang tanda baca

Tanda baca seperti titik, koma, tanda tanya dan tanda seru juga dihilangkan

Pengujian dilakukan dengan cara tiap kata yang ada pada teks update status dicocokkan dengan leksikon emosi satu persatu. Jika kata yang dicari ada pada leksikon emosi pada mendapat skor 1 dan jika tidak terdapat maka mendapat skor 0. Dengan demikian dapat diketahui berapa kata yang dapat ditemukan pada leksikon emosi dan berapa yang tidak. Total kata yang ditemukan dijumlahkan dan dibandingkan dengan jumlah leksikon emosi untuk mengetahui persentasenya. Setelah dilakukan prapemrosesan sebanyak 27.696 kata dimasukkan pada leksikon emosi yang dibuat. Hasil pengujian menunjukkan bahwa leksikon emosi mampu mendeteksi $55.45 \%$ atau 15.357 dari 27.696 yang dimasukkan.

\subsection{Deteksi Emosi dengan Leksikon Emosi}

Leksikon emosi yang sudah dibuat dan diuji, selanjutnya akan dimanfaatkan untuk mendeteksi emosi pada update status Facebook. Adapun langkah-langkanya sebagai berikut:

1. Pengambilan data

Data yang digunakan adalah update status yang diambil dari timeline pengguna Facebook. Pengguna dipilih secara acak dengan syarat menggunakan Facebook untuk media sosial pribadi, bukan jualan. Update status yang diambil hanya yang berbahasa Indonesia sebanyak 100 update status.

Tabel 4. Contoh update status yang diperoleh.

\begin{tabular}{cl}
\hline Nomor & \multicolumn{1}{c}{ Update status } \\
\hline 1 & $\begin{array}{l}\sim \text { KKN sepanjang masaaa } \\
\text { Piknik kampung syudah, pengajian akbar syudah, Idul fitri syudah, 17san syudah, tinggal idul adha aja nih.. } \\
\text { Hmm setelah idul adha masih begini gak yaa? Atau kita bakal ngilang? Hayoo ?? @ Jalan Raya Jatibaru }\end{array}$ \\
\hline 2 & $\begin{array}{l}\text { Terlalu kyut untuk tidak di pajang.. Selamat sumpah pemudaaa bagi pemuda pemudi di indonesiaa!! @ } \\
\text { Janti }\end{array}$ \\
\hline 3 & Yeayy!! Selamat mudik teman teman.. Hati hati dijalan.. See yaa ??\#teamsneakers \#mmjb \\
\hline 5 & Sayangkuh.. ?? \\
& $\begin{array}{l}\text { BAHAGIA itu adalah waktu dimana saat kita dapat tertawa lepas bersama orang orang yang selalu } \\
\text { Terimakasih @ jantibaruevents semoga buat events selanjutnya kitaa bisa buat lebih meriah lagii ya ????? }\end{array}$ \\
\hline
\end{tabular}

2. Perbaikan dengan NLP

NLP yang digunakan pada penelitian ini adalah Prosa, sebuah situs penyedia NLP Bahasa Indonesia yang dapat diakses melalui prosa.ai. NLP Prosa dapat digunakan dengan Application Programming Interface (API) yang telah disediakan. Penulis membuat program dengan bahasa pemrograman agar dapat menggunakan API yang ada.

a. Word normalizer

Word normalizer digunakan untuk memperbaiki kata-kata dalam kalimat. Word normalizer diperlukan untuk menghasilkan kalimat yang sangat baik dan benar sesuai dengan aturan tata bahasa. Peningkatan ini diperlukan untuk memudahkan pembaca memahami makna kalimat. Perbaikan dilakukan pada kata-kata yang mengalami kesalahan penulisan, ejaan, bahkan penggunaan kata-kata yang tidak standar (bahasa gaul atau bahasa asing).

Word Normalizer adalah program yang berfungsi untuk mengoreksi kata-kata non-standar (NSWs) dalam teks menjadi kata-kata yang sesuai dengan aturan tata bahasa. Input data dapat berupa teks terstruktur, seperti berita, hingga teks yang ditulis tidak terstruktur, seperti teks dari media sosial. Word normalizer memiliki 3 kemampuan yaitu perbaikan penulisan, ejaan dan kata yang tidak standar. 
Tabel 5. Contoh penggunaan Word normalizer.

\begin{tabular}{lll}
\hline Jenis kesalahan & Teks & Word normalizer \\
\hline Penulisan & Aku mau makn & Aku mau makan \\
\hline Ejaan & Bu saya mau makan. & Bu, saya mau makan. \\
\hline Kata tidak standar & Otw & Dalam perjalanan \\
\hline
\end{tabular}

\section{b. Tokenizer}

Tokenizer adalah program yang berfungsi untuk memotong teks menjadi satu set token (kata) dan/atau kalimat. Proses pemotongan kata tersebut kemudian disebut tokenization. Istilah tokenizer digunakan setelah update status diperbaiki dengan word normalizer.

Tabel 6. Contoh penggunaan tokenizer untuk memotong teks menjadi kata.

\begin{tabular}{ll}
\hline \multicolumn{1}{c}{ Teks } & \multicolumn{1}{c}{ Token kata } \\
\hline $\begin{array}{l}\text { Terlalu imut untuk tidak di pajang. Selamat sumpah } \\
\text { pemuda bagi pemuda pemudi di indonesia }\end{array}$ & $\begin{array}{l}\text { Terlalu, imut, untuk, tidak, di, pajang, selamat, sumpah, pemuda, } \\
\text { bagi, pemuda, pemudi, di, indonesia }\end{array}$ \\
\hline Bahagia itu adalah waktu dimana saat kita dapat tertawa & $\begin{array}{l}\text { Bahagian, itu, adalah, waktu, dimana, saat, kita, dapat, tertawa, } \\
\text { lepas bersama orang orang yang selalu mensupport kita } \\
\text { lepas, bersama, orang, orang, yang, selalu, mensupport, kita, } \\
\text { Terimakasih semoga buat events selanjutnya kita bisa buat } \\
\text { lebih meriah lagi ya }\end{array}$ \\
$\begin{array}{ll}\text { Orang yang hidup nya sukses itu orang yang bisa bergerak } \\
\text { dari masa lalu nya. }\end{array}$ & $\begin{array}{l}\text { Orang, yang, hidup, nya, sukses, itu, orang, yang, bisa, bergerak, } \\
\text { dari, masa, lalu, nya }\end{array}$ \\
\hline
\end{tabular}

Tabel 7. Contoh penggunaan tokenizer untuk memotong teks menjadi kalimat.

\begin{tabular}{|c|c|}
\hline \multirow{4}{*}{$\begin{array}{l}\text { Teks } \\
\text { Aku suka makan nasi goreng di kantin sekolah. Kantin } \\
\text { tersebut terletak dekat mushola. Selain nasi goreng, } \\
\text { terdapat makanan lain seperti ayam penyet. }\end{array}$} & Token kalimat \\
\hline & Aku suka makan nasi goreng di kantin sekolah. \\
\hline & Kantin tersebut terletak dekat mushola. \\
\hline & i goreng, terdapat makanan lai \\
\hline
\end{tabular}

c. Stemmer

Mengetahui bentuk kata dasar menjadi kebutuhan untuk memahami dokumen teks Indonesia. Dengan mengetahui kata-kata dasar, memahami konteks dokumen dapat dilakukan dengan lebih akurat karena mengacu pada kata-kata dasar yang sebenarnya. Stemmer dapat digunakan untuk menemukan kata dasar dari suatu kata.

Tabel 8. Contoh penggunaan stemmer.

\begin{tabular}{cc}
\hline Token kata & Stemmer \\
\hline membunuh & Bunuh \\
\hline catatan & catat \\
\hline Berbeda & beda \\
\hline meyakinkan & yakin \\
\hline dilanjutkan & lanjut \\
\hline
\end{tabular}

3. Pengujian dengan leksikon emosi

Tiap data update status yang diperoleh, satu persatu akan diuji pada leksikon yang telah dibuat sebelumnya. Tiap kata dasar dari stemmer dicek pada kamus emosi. Pada kamus emosi yang telah dibuat, satu kata bisa memiliki lebih dari satu label emosi berbeda, maka semua label emosi yang ada pada kata itu akan diambil dan diberi bobot 1 , sedangkan label emosi yang tidak ada pada kata itu akan diberi bobot 0 . Keseluruhan label emosi akan diakumulasikan dan label dengan akumulasi tertinggi dipilih sebagai label emosi update status yang diuji.

Tabel 9. Emosi dan akumulasi bobotnya.

\begin{tabular}{|c|c|c|}
\hline Token kata & Emosi & Akumulasi \\
\hline \multirow{6}{*}{$\begin{array}{l}\text { hari, yang, sangat, luar, biasa, terima, kasih, banyak, kepada, } \\
\text { keluarga, teman, sahabat, ,moga, ilmu, yang, di, dapat, manfaat, dan, } \\
\text { moga, jadi, awal, yang, baik, dari, banyak, momen, yang, bangga }\end{array}$} & Sedih & 0 \\
\hline & Bahagia & 4 \\
\hline & Marah & 1 \\
\hline & Takut & 1 \\
\hline & Jijik & 2 \\
\hline & Kaget atau terkejut & 0 \\
\hline
\end{tabular}


Pada tabel di atas diketahui bahwa bahagia memiliki akumulasi tertinggi yaitu 4, maka update status tersebut diberi label bahagia.

4. Validasi hasil pengujian

Hasil pelabelan emosi menggunakan leksikon emosi perlu divalidasi. Validasi dilakukan dengan cara survei kepada pengguna Facebook terkait sebagai pemilik status. Pengguna diberi edukasi mengenai pengertian 6 emosi Ekman agar mengerti pengertian masing-masing emosi. Survei diberikan berupa update status yang harus diisi label emosinya oleh pengguna, update status dalam survei diberikan apa adanya (yang belum diperbaiki menggunakan NLP) untuk meminimalisir salah paham pengguna.

Dari 100 update status, ada 26 update status yang dapat diketahui label emosinya. Hasil pelabelan emosi menggunakan leksikon emosi dibandingkan dengan pelabelan manual oleh pengguna terkait. Hasilnya $61,53 \%$ atau sebanyak 16 update status memiliki label emosi yang sama (akurat) dan sisanya yaitu $38,47 \%$ tidak akurat.

\section{Kesimpulan}

Perhitungan emosi dari teks adalah bidang baru-baru ini. Dalam linguistik, perhitungan otomatis dan deteksi emosi dari teks menjadi salah satu topik yang sangat banyak diteliti. Salah satu pendekatan mendeteksi emosi dari teks adalah leksikon, EmoLex merupakan leksikon emosi yang tersedia dalam 105 bahasa di dunia salah satunya Indonesia yang memuat 14.182 kata. Kateglo API sebuah tesaurus bahasa Indonesia dapat dimanfaatkan untuk memperluas EmoLex dengan mencarikan sinonim tiap kata yang ada pada EmoLex menjadi 20.690 kata. Hasil pengujian menunjukkan bahwa leksikon emosi mampu mendeteksi $55.45 \%$ atau 15.357 dari 27.696 kata yang diperoleh dari update status pengguna Facebook. NLP dapat dimanfaatkan untuk memperbaiki teks yang berasal dari update status. Hasil perbaikan dari NLP dicocokkan dengan leksikon yang telah dibuat untuk mengetahui label emosi dari suatu update status. Sebanyak 26 update status dapat terdeteksi label emosinya dan 61,53\% di antaranya akurat.

Peneliti berharap pada penelitian selanjutnya dapat meningkatkan nilai akurasi dari pelabelan emosi. Meningkatkan prapemrosesan dengan membuang nama orang, nama tempat dan kata sambung, serta kata yang tidak baku dalam bahasa Indonesia.

\section{Daftar Pustaka}

[1] S. Grover and A. Verma, "Design for emotion detection of punjabi text using hybrid approach," in Proceedings of the International Conference on Inventive Computation Technologies, ICICT 2016, 2017, vol. 2.

[2] M. P. Skenduli, M. Biba, C. Loglisci, M. Ceci, and D. Malerba, "User-Emotion Detection Through Sentence-Based Classification Using Deep Learning: A Case-Study with Microblogs in Albanian Marjana," Lecture Notes in Computer Science (including subseries Lecture Notes in Artificial Intelligence and Lecture Notes in Bioinformatics), vol. 11177 LNAI, Springer International Publishing, pp. v-vi, 2018.

[3] E. Hamdi, A Convolutional Neural Network Model for Emotion Detection from Tweets. Springer International Publishing, 2019.

[4] S. X. Mashal and K. Asnani, "Emotion intensity detection for social media data," Proc. Int. Conf. Comput. Methodol. Commun. ICCMC 2017, vol. 2018-Janua, no. Iccmc, pp. 155-158, 2018.

[5] M. Abdullah, M. Hadzikadicy, and S. Shaikhz, "SEDAT: Sentiment and Emotion Detection in Arabic Text Using CNN-LSTM Deep Learning," in Proceedings - 17th IEEE International Conference on Machine Learning and Applications, ICMLA 2018, 2019, pp. 835-840.

[6] M. Deshpande and V. Rao, "Depression detection using emotion artificial intelligence," Proc. Int. Conf. Intell. Sustain. Syst. ICISS 2017, no. Iciss, pp. 858-862, 2018.

[7] I. Oyong, E. Utami, and E. T. Luthfi, "Natural language processing and lexical approach for depression symptoms screening of Indonesian twitter user," Proc. 2018 10th Int. Conf. Inf. Technol. Electr. Eng. Smart Technol. Better Soc. ICITEE 2018, pp. 359-364, 2018.

[8] S. Al-Saaqa, H. Abdel-Nabi, and A. Awajan, "A Survey of Textual Emotion Detection," in 2018 8th International Conference on Computer Science and Information Technology, CSIT 2018, 2018, pp. 136-142.

[9] Muljono, A. S. Winarsih, and C. Supriyanto, "Evaluation of classification methods for Indonesian text emotion detection,” Proc. - 2016 Int. Semin. Appl. Technol. Inf. Commun. ISEMANTIC 2016, pp. $130-133,2016$.

[10] T. Moers, F. Krebs, and G. S. B, SEMTec: Social Emotion Mining Techniques for Analysis and Prediction of Facebook Post Reactions, vol. 449. Springer International Publishing, 2018. 